\title{
Development and preliminary evaluation of a quality of life measure targeted at dementia caregivers
}

\author{
Barbara G Vickrey*1, Ron D Hays ${ }^{2}$, Michele L Maines ${ }^{1}$, Stefanie D Vassar ${ }^{1}$, \\ Jaime Fitten ${ }^{3}$ and Tony Strickland ${ }^{1}$
}

Address: ${ }^{1}$ University of California, Los Angeles Department of Neurology, 710 Westwood Plaza, Los Angeles, California 90095-1769, USA, ${ }^{2}$ UCLA Department of Medicine, Division of General Internal Medicine \& Health Services Research, 911 Broxton Plaza, Los Angeles, California, 900951736, USA and ${ }^{3}$ UCLA Department of Psychiatry and Biobehavioral Sciences, 760 Westwood Plaza, Los Angeles, California, 90095-1759, USA

Email: Barbara G Vickrey* - bvickrey@ucla.edu; Ron D Hays - drhays@ucla.edu; Michele L Maines - mmaines@ucla.edu; Stefanie D Vassar - svassar@ucla.edu; Jaime Fitten - jfitten@ucla.edu; Tony Strickland - tstrick@ucla.edu

* Corresponding author

Published: 21 June 2009

Health and Quality of Life Outcomes 2009, 7:56 doi:10.1 186/1477-7525-7-56
Received: 17 November 2008

Accepted: 21 June 2009

This article is available from: http://www.hqlo.com/content/7/I/56

(c) 2009 Vickrey et al; licensee BioMed Central Ltd.

This is an Open Access article distributed under the terms of the Creative Commons Attribution License (http://creativecommons.org/licenses/by/2.0), which permits unrestricted use, distribution, and reproduction in any medium, provided the original work is properly cited.

\begin{abstract}
Background: Providing care for individuals with a progressive, debilitating condition such as dementia can adversely impact the quality of life (QOL) of informal caregivers. To date, there is no existing caregiver quality of life measure for dementia caregivers with breadth of coverage or that is applicable to caregivers of diverse ethnic backgrounds. The purpose of this study was to develop and evaluate a caregiver-targeted quality-of-life measure (CGQOL) for informal caregivers of persons with dementia that can be used with caregivers from a variety of ethnicities.
\end{abstract}

Methods: 91 items were field tested by telephone interviews with 179 English-speaking and 21 monolingual Spanish-speaking caregivers of persons with dementia. Repeat interviews were conducted with $7 \mathrm{I}$ caregivers. Administration time, scale score distributions, item-scale correlations, reliability, and associations of scales with patient and caregiver demographic and caregiving characteristics were estimated. Structure of associations among scales was examined using exploratory factor analysis.

Results: Item analysis yielded 80 items distributed across 10 scales, with median administration time of 17 minutes [IQR 13.5-22 minutes] and minimal missing data. There were few floor or ceiling effects in scale score distributions. Internal consistency reliability was $\geq 0.78$ for all scales; test-retest reliability (intraclass correlation) estimates exceeded 0.70 for 6 scales. More hours weekly spent in caregiving was uniquely associated with worse quality of life on 8 scales ( $p$ 's $\leq 0.05$ ). Three higher-order dimensions of caregiving assistance, emotional and social concerns, and spirituality and benefits were identified.

Conclusion: These preliminary results support subsequent evaluation of test-retest reliability, construct validity, and responsiveness to change of this quality-of-life measure for caregivers from diverse ethnicities. 


\section{Background}

The occurrence of Alzheimer's disease (AD) and related dementias accompanied by pervasive memory loss and associated behavioral disturbance is a major public health concern among older adults. The most rapidly growing segment of our population is that over the age of 80 , and dementia is the most common cause of disability among these individuals [1].

Those with dementia eventually become totally dependent on one or more caregivers over the course of the illness. While a large proportion of persons with dementia are cared for in institutions, more than half receive care at home from spouses and other family members [2]. The largest proportion of patients with dementia receiving care in the home is among ethnic minorities, which significantly exacerbates challenged family dynamics via increased role and economic strains.

Providing care for individuals with a progressive, debilitating condition such as dementia can adversely impact the quality of life (QOL) of informal caregivers in many ways. Studies to assess the impact of new treatments or new ways of delivering care for people with dementia should incorporate instruments that very broadly address not only domains of health-related quality of life, but also non health-related quality of life, because these dimensions (for example, perceptions of family involvement in caregiving, caregiver's perceptions of having personal time away from caregiving) likely affect outcomes relevant to patients such as time to institutionalization. Our first step was to assess what kinds of caregiver measures were available in the literature. We conducted a literature search (updated in October 2008) using the PubMed, PsychINFO and AgeLine databases and using search terms dementia caregiver and quality of life, and we searched the MAPI Institute's online catalog of QOL measures http:// www.proqolid.org. We found that with one exception, published studies of dementia caregiver quality of life had used generic quality-of-life measures or targeted narrower constructs of burden or depression. The only exception is a measure developed by the PIXEL study group [3].

Caregivers are more likely to be depressed and anxious and experience increased risk of physical health problems than non-caregivers [4]. Numerous research studies have demonstrated an association between caring for a loved one with dementia and the development of caregiver stress and burden [5]. Families often report that behavioral disturbances are the primary source of stress and the primary cause for institutionalization of their loved one $[4,6,7]$. Additionally, dementia has the effect of segregating caregivers from others because of the care needs and problem behaviors of dementia sufferers. Relationship strain between the caregiver and the dementia sufferer, and social isolation are negative consequences associated with assisting the dementia sufferer [8]. Furthermore, if the person with dementia is institutionalized, the caregiver may grieve for the loss of the relationship, another source of caregiver stress [9]. In effect, caregivers may experience declines in their physical, mental, and social health. These adverse health outcomes for caregivers may impact the use of patient services (including long-term care facilities) and outcomes of the person with dementia [6].

The construct of caregiver burden embodies only negative physical, psychological, social and financial demands of providing care for someone with dementia [5], for example, as assessed by the Zarit Caregiver Burden Interview [10]. Another negative caregiving outcome is depressive symptomatology, assessed using tools such as the Center for Epidemiologic Studies-Depression (CES-D) scale [11], the Geriatric Depression Scale (GDS) [12], or the Zung Depression Rating Scale (ZDRS) [13].

Measures of QOL include constructs such as physical, emotional and cognitive functioning, self-rated health, self-efficacy, spirituality, financial status, social support, and satisfaction with life situations among others $[14,15]$. Generic health-related quality of life measures used in studies of dementia caregivers include the EuroQol (EQ5D) [16], Health Utilities Index Mark 2 (HUI-2) [17], and Short Form-36 Health Survey (SF-36) [18]. The sole published dementia-caregiving-targeted QOL measure was developed in the PIXEL study in France [3]. This instrument includes 20 dichotomous (yes/no) items that focus on four domains that are all negative aspects of caregiving (behavioral competence, relation to environment, psychological perceptions of the situation, and perception of distress) without addressing positive aspects such as benefits or spirituality and faith. The PIXEL measure does not capture the extent of care provided by the caregiver to the patient or assistance received by the caregiver either from family or another source.

We embarked on development of a comprehensive measure of both health-related and non-health-related quality of life for dementia caregivers, to fill the gap in the literature on such a tool. Our goal was to develop a measure that could be used in a diverse group of caregivers of multiple ethnicities and a wide range of education levels. We previously conducted six focus groups ( 2 groups predominantly Caucasian; 1 group Hispanic and conducted in Spanish; 1 group Chinese-American; 2 groups AfricanAmerican) and 29 cognitive interviews (21 in English and 8 in Spanish) with ethnically diverse samples of caregivers of persons with a diagnosis of dementia. We then developed a draft set of caregiver quality-of-life items based on domains that were identified as key in assessing caregiver 
quality of life: caregiving assistance, personal time, family involvement, caregiving demands, worry, spirituality and faith, benefits of caregiving, caregiver feelings, and role limitations due to caregiving [19]. Spirituality and faith, and benefits of caregiving were domains uniquely identified by caregivers from minority groups. The goal of the study reported herein was to field test this item set, with the goal of developing a standardized caregiver quality of life instrument (CGQOL) in English and Spanish for use by the larger research community to assess quality of life for caregivers of persons with cognitive impairment.

\section{Methods}

\section{Sample}

Initially, 51 caregivers were recruited from consecutive patient/caregiver dyads enrolled in the UCLA Alzheimer's Disease Center longitudinal registry study [20]. The final 149 caregivers of persons with dementia or Alzheimer's disease were recruited using flyers posted in public locations and announcements in newsletters and websites. Criteria for enrollment required caregivers to be non-professional caregivers, be 18 years of age or older, live in Southern California, and be English or Spanish speaking. Informed consent was obtained from each subject prior to being interviewed at all time periods.

\section{Measures}

A field test set of 91 items assessing aspects of caregiver quality of life was generated based on analysis of data from focus groups of caregivers from diverse ethnic groups in the southern California area [19]. These items tapped caregiving assistance (activities of daily living (ADLs) and instrumental activities of daily living (IADLs)), personal time, family involvement, caregiving demands, worry, spirituality and faith, benefits of caregiving, caregiver feelings, and role limitations due to caregiving. Some of the items and response scales were adapted from measures developed in the Medical Outcomes Study [21]. Field test items were translated into Spanish by one experienced translator, reviewed by a second translator, then administered to eight Spanish-speaking caregivers in a series of cognitive interviews, to assess and refine the wording [22,23]. Additional data that were collected by interview or from an existing database were patient and caregiver age, gender, ethnicity, marital status, and education; relationship of the caregiver to the patient; hours spent weekly in caregiving; duration of caregiving; average number of months as primary caregiver in the prior year; and unmet need for caregiving assistance. Unmet need was assessed by asking caregivers to rate the degree to which they were bothered by needing more help than was received and by the lack of help received from family members. Responses were provided on a 1-5 scale (not at all bothered $=1$; extremely bothered $=5$ ). An overall rating of the caregiving experience on a 0-10 scale (worst =
0 ; best $=10)$ and a rating of the severity of the patient's dementia (mild, intermediate, advanced) were also obtained.

\section{Data collection}

An initial telephone interview was completed between May 2001 and July 2006. We collected these data by telephone interview because our goal was for the measure to be used in socioeconomically disadvantaged populations, including those with very low or no formal education and unable to read or write. This interview included demographic questions about the patient and caregiver, and the 91-question field test item set about quality of life as a caregiver for a person with dementia. The demographic questions in the interviews of the later group of 149 caregivers were expanded to include more questions about caregiver characteristics (age, marital status, ethnicity, education) than were available for the initial 51 subjects. Selected patient variables (age, marital status, ethnicity, and education) for the initial set of 51 caregivers were obtained from the Alzheimer's Disease registry database rather than from interview. A \$10 payment was sent to each participant following each interview. To assess test-retest reliability, a subsample of 71 caregivers (51 English speaking and 20 Spanish speaking) completed a second telephone interview, identical to the first, 11 to 63 days after the initial interview (75\% within 21 days).

Study activities were performed with the approval of the UCLA Office for Protection of Research Subjects (approval \#G04-03-089-12).

\section{Analysis}

Analyses were conducted using SAS version 9.1. All items were transformed linearly to have a $0-100$ possible range, where higher values mean better caregiver quality of life in that domain [24]. Multitrait scaling was used to assess item convergence and discrimination across the ten dimensions/hypothesized scales [25]. Items that had higher correlations with a scale other than the hypothesized scale were moved, and the multitrait scaling analysis was run again. Items loading on more than one scale (applying in general a rule of loadings that were within one standard error or 0.076 of each other), and items that had no item-scale correlation greater than 0.35 were excluded from the final measure.

Scale scores were calculated by taking the mean of the final set of items included in each scale. For each scale the mean score, standard deviation (SD), observed minimum, and percent of subjects with minimum and maximum scores were calculated. Cronbach's alpha was used to estimate internal consistency for each multi-item scale [26]. Test-retest reliabilities and 95\% confidence intervals around those estimates were generated using intraclass 
Table I: Caregiver Characteristics and Perceptions ${ }^{\mathbf{a}}$

\begin{tabular}{|c|c|}
\hline & $\mathbf{N}(\%)$ \\
\hline Age (mean, SD) $(n=147)$ & $61.5(13.5)$ \\
\hline \multicolumn{2}{|l|}{ Gender $(n=200)$} \\
\hline Male & $43(22)$ \\
\hline Female & $157(79)$ \\
\hline \multicolumn{2}{|l|}{ Ethnicity $(n=148)$} \\
\hline White & $97(66)$ \\
\hline African American & $13(9)$ \\
\hline Asian & $10(7)$ \\
\hline Hispanic & $27(18)$ \\
\hline Other & $I(I)$ \\
\hline
\end{tabular}

Marital Status $(n=178)$

\begin{tabular}{|c|c|}
\hline Married & $115(65)$ \\
\hline Never Married & $34(19)$ \\
\hline Separated & $6(3)$ \\
\hline Divorced & $18(10)$ \\
\hline Widowed & $5(3)$ \\
\hline \multicolumn{2}{|l|}{ Education $(n=147)$} \\
\hline 8th grade of less & $5(3)$ \\
\hline Some high school & $4(3)$ \\
\hline High school grad & $12(8)$ \\
\hline Some college & $48(33)$ \\
\hline 4-year degree & $43(29)$ \\
\hline More than 4-year degree & $35(24)$ \\
\hline \multicolumn{2}{|l|}{ Relationship $(n=200)$} \\
\hline Spouse & $89(45)$ \\
\hline Child/Child-in-law & $85(43)$ \\
\hline Sibling/Sibling-in-law & $7(4)$ \\
\hline Niece/Nephew & $2(1)$ \\
\hline
\end{tabular}


Table I: Caregiver Characteristics and Perceptions ${ }^{\mathbf{a}}$ (Continued)

\begin{tabular}{ll}
\hline Grandchild & $3(2)$ \\
\hline Friend & $8(4)$ \\
\hline Other & $6(3)$ \\
\hline Hours spent each week caring for relative/friend with dementia $(n=200)$ & $23(12)$ \\
\hline $0-5$ hours & $26(13)$ \\
\hline $6-10$ hours & $19(9)$ \\
\hline $11-20$ hours & $110)$ \\
\hline More than 30 hours 30 hours
\end{tabular}

Time being a caregiver to relative/friend with dementia $(n=200)$

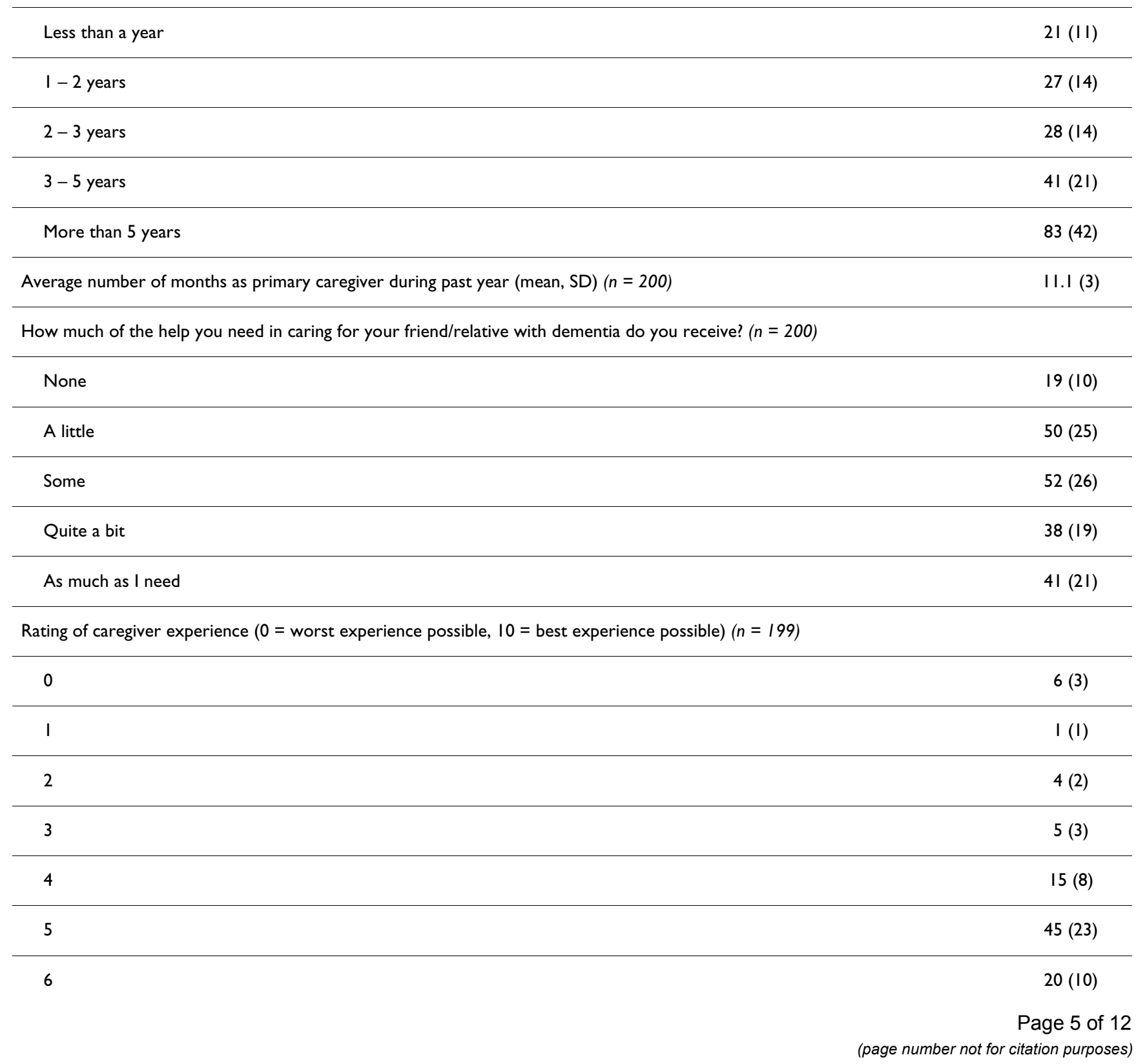


Table I: Caregiver Characteristics and Perceptions ${ }^{\mathbf{a}}$ (Continued)

\begin{tabular}{cc}
\hline \hline 7 & $22(11)$ \\
\hline 8 & $40(20)$ \\
\hline 9 & $22(11)$ \\
\hline 10 & $19(10)$ \\
\hline
\end{tabular}

a Caregiver age, gender, and ethnicity were only collected during the telephone interview of the later group of I49 caregiver enrollees. All other characteristics were obtained from all subjects during the telephone interview.

Table 2: Patient characteristics and perceptions a

\begin{tabular}{lc}
\hline & N (\%) \\
\hline Patient Characteristics & $80.2(10)$ \\
\hline Age $($ mean, SD) $(n=198)$ & $86(43)$ \\
\hline Gender $(n=198)$ & $112(57)$ \\
\hline Male & $140(71)$ \\
\hline Female & $14(7)$ \\
\hline Whicity $(n=196)$ & $14(7)$ \\
\hline African American & $27(14)$ \\
\hline Hispanic & $1(1)$ \\
\hline Other
\end{tabular}

Marital Status $(n=198)$

\begin{tabular}{lc}
\hline Married & $104(53)$ \\
\hline Never Married & $10(5)$ \\
\hline Separated & $1(1)$ \\
\hline Divorced & $18(9)$ \\
\hline Widowed & $65(33)$ \\
\hline Education ( $n=194)$ & $17(9)$ \\
\hline 8th grade of less & $8(4)$ \\
\hline Some high school
\end{tabular}

Table 2: Patient characteristics and perceptions a (Continued)

\begin{tabular}{lc}
\hline High school grad & $58(30)$ \\
\hline Some college & $40(2 \mathrm{I})$ \\
\hline 4-year degree & $41(2 \mathrm{I})$ \\
\hline More than 4-year degree & $30(16)$ \\
\hline Dementia Severity $(n=144)$ & $25(17)$ \\
\hline Mild & $86(60)$ \\
\hline Intermediate & $33(23)$ \\
\hline Advanced
\end{tabular}

a Dementia severity was only collected during the telephone interview of the later group of I49 caregiver enrollees. Patient age, gender, ethnicity, martial status and education were obtained from the Alzheimer's Disease registry database for the initial set of $5 \mathrm{I}$ caregivers (when available) and during the telephone interview for the later group of 149 caregivers.

correlations between baseline and follow-up scores of 38 subjects who had a repeat interview within 21 days of the initial interview and who had a 1-point or no change in their overall rating of their caregiving experience (on a $0-$ 10 scale) between the two interview dates.

Associations of patient and caregiver characteristics with caregiver quality-of-life scale scores were analyzed using Pearson or Spearman correlations or analysis of variance (ANOVA), as appropriate. Backwards stepwise regression was used to quantify the extent of unique relationships between each of the 10 caregiver quality-of-life scale scores (dependent variables) and these caregiver and patient characteristics: patient and caregiver age, gender, ethnicity, marital status, and education, caregiver's relationship to person with dementia, hours each week spent caring for person with dementia, number of years being a caregiver for person with dementia, and level of unmet need for caregiving assistance. For our bivariate and multivariate analyses of construct validity, we hypothesized 
that we would consistently observe associations of better quality-of-life with shorter duration of being a caregiver, fewer hours per week in caregiving, being a male caregiver, and milder dementia. Based on data from our earlier focus groups, we hypothesized that caregivers who were nonwhite would more strongly endorse spirituality and faith and benefits of caregiving compared to caregivers who were white. We anticipated that associations of caregiver quality of life with other caregiver and patient characteristics would be minimal or non-significant. Caregiver age, marital status, ethnicity and education were not collected for the initial group 51 of caregivers; patient age, gender, ethnicity, education and marital status were missing for a few patients in that caregiver subgroup, as well. Our imputation rule for subjects with missing data on these variables was to use the sample mean of subjects with nonmissing data for the particular variable.
Higher order associations of individual scales were evaluated using factor analysis. Several number of factor criteria were run, including Guttman's weakest lower bound, Cattell's scree test, and parallel analysis. These indicated that 2- or 3-factor solutions were appropriate. Factor analysis was conducted using a Promax rotated factor solution.

\section{Results}

Mean caregiver age was 61.5 years and mean patient age was 80.2 years (See Tables 1 and 2). Seventy-nine percent of caregivers and $57 \%$ of patients were female. The caregiver was a spouse of the patient $45 \%$ of the time, and $43 \%$ were an adult-child/child-in-law. Spanish was the primary language among $11 \%$ of the caregivers. Fiftythree percent of caregivers and $37 \%$ of patients had at least a 4-year college degree. Over half of caregivers provided more than 30 hours of caregiving each week, and $42 \%$ had been caregiving for more than 5 years. Of the 144 caregiv-

Table 3: Descriptive statistics and reliability estimates a

\begin{tabular}{|c|c|c|c|c|c|c|c|}
\hline Scale & No. of items & Mean (SD) & $\begin{array}{l}\text { Observed } \\
\text { minimum }\end{array}$ & $\begin{array}{c}\% \text { Scoring at floor } \\
(0 \text { points })\end{array}$ & $\begin{array}{l}\text { \% Scoring at } \\
\text { ceiling } \\
\text { (100 points) }\end{array}$ & Cronbach's alpha & $\begin{array}{c}\text { Test-retest } \\
\text { reliability } \\
(\mathrm{ICC}, 95 \% \mathrm{Cl}) \mathrm{b}\end{array}$ \\
\hline $\begin{array}{l}\text { Assistance in } \\
\text { IADLS c }\end{array}$ & 13 & $21.6(21.7)$ & 0 & 20.0 & 0.5 & 0.88 & $\begin{array}{c}0.86 \\
(0.73-0.99)\end{array}$ \\
\hline $\begin{array}{l}\text { Assistance in } \\
\text { ADLS } d\end{array}$ & 5 & $\begin{array}{c}63.0 \\
(36.2)\end{array}$ & 0 & 12.5 & 26.5 & 0.93 & $\begin{array}{c}0.86 \\
(0.7 I-1.00)\end{array}$ \\
\hline Personal Time & 4 & $\begin{array}{c}45.2 \\
(23.2)\end{array}$ & 0 & 2.0 & 0.0 & 0.78 & $\begin{array}{c}0.63 \\
(0.34-0.92)\end{array}$ \\
\hline $\begin{array}{l}\text { Role Limitations } \\
\text { Due to Caregiving }\end{array}$ & 5 & $\begin{array}{c}50.7 \\
(24.2)\end{array}$ & 0 & 1.0 & 1.5 & 0.83 & $\begin{array}{c}0.53 \\
(0.20-0.86)\end{array}$ \\
\hline $\begin{array}{l}\text { Family } \\
\text { Involvement }\end{array}$ & 6 & $\begin{array}{r}52.6 \\
(26.7)\end{array}$ & 0 & 1.0 & 6.5 & 0.86 & $\begin{array}{c}0.74 \\
(0.53-0.96)\end{array}$ \\
\hline $\begin{array}{l}\text { Demands of } \\
\text { Caregiving }\end{array}$ & 7 & $\begin{array}{c}50.9 \\
(23.2)\end{array}$ & 3.6 & 0.0 & 2.0 & 0.86 & $\begin{array}{c}0.72 \\
(0.50-0.95)\end{array}$ \\
\hline Worry & 9 & $\begin{array}{c}50.2 \\
(20.3)\end{array}$ & 2.8 & 0.0 & 0.0 & 0.82 & $\begin{array}{c}0.53 \\
(0.17-0.89)\end{array}$ \\
\hline $\begin{array}{l}\text { Caregiver } \\
\text { Feelings }\end{array}$ & 20 & $\begin{array}{c}66.0 \\
(20.5)\end{array}$ & 1.3 & 0.0 & 1.0 & 0.94 & $\begin{array}{c}0.65 \\
(0.33-0.97)\end{array}$ \\
\hline $\begin{array}{l}\text { Spirituality and } \\
\text { Faith }\end{array}$ & 3 & $\begin{array}{c}63.5 \\
(34.8)\end{array}$ & 0 & 12.1 & 26.1 & 0.92 & $\begin{array}{c}0.83 \\
(0.65-1.00)\end{array}$ \\
\hline $\begin{array}{l}\text { Benefits of } \\
\text { Caregiving }\end{array}$ & 8 & $\begin{array}{c}68.9 \\
(23.0)\end{array}$ & 3.1 & 0.0 & 5.5 & 0.89 & $\begin{array}{c}0.89 \\
(0.79-0.99)\end{array}$ \\
\hline
\end{tabular}

a Higher values mean better functioning and well-being or need for less assistance from caregiver. $\mathrm{n}=199-200$ caregivers except for testretest reliability

${ }^{b} \mathrm{n}=38$ caregivers with one point or less change in caregiver experience and $2 \mid$ days or less (mean $=\mid 4.9$ days, $\left.S D=3.2\right)$ between baseline and retest.

c IADLS = Instrumental Activities of Daily Living

dADLS = Activities of Daily Living 
Table 4: Promax rotated three factor solution for the 10 caregiver quality of life scales a

\begin{tabular}{|c|c|c|c|}
\hline Scale & Tangible Assistance & Psychosocial & Benefits/Faith \\
\hline Assistance in IADLS b & 0.73 & & \\
\hline Assistance in ADLS c & 0.47 & & \\
\hline Personal Time & 0.54 & & \\
\hline Role Limitations Due to Caregiving & 0.41 & 0.41 & \\
\hline Family Involvement & & 0.56 & \\
\hline Demands of Caregiving & & 0.75 & \\
\hline Worry & & 0.74 & \\
\hline Caregiver Feelings & & 0.77 & \\
\hline Spirituality and Faith & & & 0.64 \\
\hline Benefits of Caregiving & & & 0.66 \\
\hline
\end{tabular}

a Standardized regression coefficients of the factors on the scales. Factor pattern loadings $>=0.30$ are shown.

Estimated correlations among factors: tangible assistance with psychosocial $=0.52$, tangible assistance with benefits/faith $=0.04$, psychosocial with benefits/faith $=0.18$.

b IADLS = Instrumental Activities of Daily Living

c ADLS = Activities of Daily Living

ers from whom the patient's dementia severity was asked in the interview, $17 \%$ indicated it was mild, $60 \%$ indicated it was intermediate, and 23\% reported the severity of dementia as advanced.

There was only one missing or refusal response for the 91 items across the 200 subjects. Administration time was recorded for 76 subjects, and the median administration time for the 91 quality-of-life items and 19 other questions was 23.5 minutes (interquartile range 18.5 to 30 ).

We performed 8 iterations of multitrait scaling. Item analyses resulted in 80 final items (out of 91 in the field test item set) in the caregiver quality of life measure, distributed across 10 scales (See Table 3 and Additional Files 1 and 2: CGQOL 80-item Measure and CGQOL Scoring Manual): assistance with ADLs (5 items), assistance with IADLs (13 items), personal time (4 items), role limitations due to caregiving ( 5 times), family involvement ( 6 items), demands of caregiving (7 items), worry (9 items), caregiver feelings (20 items), spirituality and faith (3 items) and benefits of caregiving ( 8 items). Seven items were excluded because two item-scale correlations had similar loadings, and another four items were excluded because no item-scale correlation was greater than 0.35 .

Mean scale scores ranged from 21.6 (assistance with IADLs) to 68.9 (benefits of caregiving). There were few floor and ceiling effects, with the largest ceiling effects on assistance with ADLs (27\%) and on spirituality and faith $(26 \%)$; the largest floor effect was on assistance with IADLs (20\%). Cronbach's alpha ranged from 0.78 to 0.94 ; intraclass correlation coefficients for test-retest reliability ranged from 0.53 (role limitations due to caregiving; worry) to 0.89 (benefits of caregiving), exceeding 0.70 for 6 of the 10 scales (See Table 3).

A three-factor solution was interpreted as showing higher order dimensions of tangible assistance, psychosocial, and benefits/faith (See Table 4). Associations between factors ranged from 0.04 to 0.52 .

Bivariate associations (See Additional File 3: Table S1) were most consistently observed between caregiver quality-of-life scales and hours per week spent caregiving, where more hours per week caregiving was negatively associated with all scales ( $\mathrm{p}$ 's $<0.01)$ except for spirituality and faith and for benefits of caregiving $(p \geq 0.05)$ ). In contrast, there were few associations of duration of being a caregiver and caregiver quality-of-life scores. Non-white ethnicity of both the caregiver and of the patient were substantially associated with spirituality and faith and with benefits of caregiving ( $p$ 's $<0.0001$ ). Older caregivers had less worry, better family involvement, and provided less assistance with ADLs, but younger caregiving age was associated with higher spirituality and faith and higher 
Table 5: Caregiver quality of life scales regressed on patient and caregiver characteristics a

\begin{tabular}{|c|c|c|c|c|c|}
\hline & $\begin{array}{c}\text { Adjusted } \\
\mathrm{R}^{2}\end{array}$ & Unstandard-ized beta & Standard Error & t-test statistic & $P$-value \\
\hline Assistance in IADLS & 0.47 & & & & \\
\hline Caregiving hours per week & & -10.13 & 0.82 & -12.42 & $<0.001$ \\
\hline Assistance in ADLS & 0.30 & & & & \\
\hline Patient male & & 12.87 & 4.78 & 2.69 & 0.008 \\
\hline Caregiving hours per week & & -9.77 & 1.64 & -5.97 & $<0.001$ \\
\hline Caregiver white & & 37.91 & 9.77 & 3.88 & $<0.001$ \\
\hline Personal Time & 0.41 & & & & \\
\hline Less unmet need for caregiving assistance & & 0.22 & 0.04 & 5.36 & $<0.001$ \\
\hline Caregiving hours per week & & -7.76 & 0.94 & -8.26 & $<0.001$ \\
\hline Role Limitations Due to Caregiving & 0.27 & & & & \\
\hline Less unmet need for caregiving assistance & & 0.18 & 0.05 & 3.76 & $<0.001$ \\
\hline Caregiver is child & & $-11.6 \mid$ & 3.28 & -3.54 & $<0.001$ \\
\hline Caregiver white & & -7.97 & 3.66 & -2.17 & 0.03 \\
\hline Caregiving hours per week & & -6.93 & 1.09 & -6.35 & $<0.001$ \\
\hline Family Involvement & 0.37 & & & & \\
\hline Less unmet need for caregiving assistance & & 0.38 & 0.05 & 7.45 & $<0.001$ \\
\hline Patient married & & 9.17 & 4.09 & 2.24 & 0.03 \\
\hline Caregiver is child & & -13.76 & 3.77 & -3.65 & $<0.001$ \\
\hline Caregiving hours per week & & -2.22 & 1.11 & -1.99 & 0.05 \\
\hline Demands of Caregiving & 0.19 & & & & \\
\hline Less unmet need for caregiving assistance & & 0.16 & 0.05 & 3.26 & 0.001 \\
\hline Caregiver male & & 7.71 & 3.64 & 2.12 & 0.04 \\
\hline Caregiver is child & & $-|3.9|$ & 3.42 & -4.07 & $<0.001$ \\
\hline Caregiving hours per week & & -3.72 & 1.09 & -3.39 & 0.001 \\
\hline Worry & 0.21 & & & & \\
\hline Less unmet need for caregiving assistance & & 0.10 & 0.04 & 2.44 & 0.02 \\
\hline Caregiving hours per week & & -2.72 & 0.96 & -2.84 & 0.005 \\
\hline Caregiver male & & 7.18 & 3.20 & 2.25 & 0.03 \\
\hline Caregiver is child & & -10.09 & 4.11 & -2.46 & 0.02 \\
\hline Caregiver at least college degree & & 6.84 & 3.16 & 2.16 & 0.03 \\
\hline Caregiver age & & 0.35 & 0.13 & 2.63 & 0.009 \\
\hline Caregiver Feelings & 0.24 & & & & \\
\hline Less unmet need to caregiver assistance & & 0.10 & 0.04 & 2.30 & 0.02 \\
\hline Patient male & & -10.75 & 3.11 & -3.45 & 0.001 \\
\hline Caregiver is child & & -11.68 & 3.08 & -3.80 & $<0.001$ \\
\hline Caregiving hours per week & & -3.11 & 0.96 & -3.25 & 0.001 \\
\hline Spirituality and Faith & 0.27 & & & & \\
\hline Patient age & & -0.80 & 0.22 & -3.67 & $<0.001$ \\
\hline Patient at least college degree & & -20.03 & 4.58 & -4.37 & $<0.001$ \\
\hline Caregiver white & & -18.86 & 5.34 & -3.53 & $<0.001$ \\
\hline Caregiver male & & -14.44 & 5.18 & -2.79 & 0.006 \\
\hline Caregiver married & & -12.78 & 4.92 & -2.59 & 0.01 \\
\hline Benefits of Caregiving & 0.16 & & & & \\
\hline Caregiver white & & -15.89 & 3.90 & -4.07 & $<0.001$ \\
\hline Patient at least college education & & -6.67 & 3.17 & -2.10 & 0.04 \\
\hline Caregiver age & & -0.31 & 0.14 & -2.19 & 0.03 \\
\hline
\end{tabular}

$a_{n}=200$. Ba ckwards stepwise regression models with $p>0.2$ for removal from model. Listed independent variables with $p<0.05$. Independent variables available for inclusion in the model: patient and caregiver age, gender, ethnicity, marital status, and education, caregiver's relationship to person with dementia, hours each week spent caring for person with dementia, number of years being a caregiver for person with dementia, and unmet need for caregiving assistance. Means were imputed for caregiver age, marital status, ethnicity and education and patient age, gender, marital status, ethnicity and education where these data were unavailable or missing. 
benefits of caregiving scores ( $\mathrm{p}$ 's $<0.01$ ). Less unmet need with caregiving assistance was associated with higher caregiver quality of life on 8 of 10 scales (all $p \leq 0.01$ ).

Regression models confirmed the unique and consistent associations of more weekly caregiving hours with worse caregiver quality of life, except for no association with spirituality and faith or with benefits of caregiving (See Table 5). More unmet need for caregiving assistance was uniquely associated with 6 of the 10 scales (all p's $<0.05$ ): personal time, role limitations due to caregiving, family involvement, demands of caregiving, caregiver worry, and caregiver feelings (See Table 5). Less patient education and non-white caregiver ethnicity were associated with higher spirituality and faith and higher benefits of caregiving scale scores. Demands of caregiving and caregiver feelings were worse for caregivers who were children.

\section{Discussion}

We previously identified 10 dimensions of quality of life as relevant to caregivers of persons with dementia, based on focus groups of Hispanic, Caucasian, African-American, and Chinese-American caregivers. These dimensions were not limited to health-related aspects of quality of life, but were intended to incorporate non-health related issues and positive aspects of caregiving. Based on these focus group data, we developed a set of items; in this field test, we found that telephone administration of both English and Spanish-language versions of this item set was highly feasible, with only one of 200 subjects refusing to answer one item out of 91 . We estimate median administration time for the 80 items to be 17.1 minutes (interquartile range estimated as 13.5 to 22 minutes). Examination of item-scale correlations enabled us to reduce the number of items in the final CGQOL measure to 80 . Final scale score distributions were reasonable, with few floor or ceiling effects. Internal consistency reliability was excellent; however, test-retest reliability was adequate for only 6 of 10 scales. Because our sample was relatively small and confidence intervals around these estimates wide, further evaluation in a larger sample should be conducted.

We were able to assess selected aspects of construct validity in this study. As hypothesized [27], of 8 of 10 scales in the CGQOL measure with extent of caregiving, as measured by weekly hours in caregiving, were strong; the two scales not associated with weekly hours in caregiving were those tapping more intangible aspects of caregiving: spirituality and faith, and benefits. However, in contrast to our expectations, duration of caregiving was not uniquely associated with caregiver quality of life, possibly because the associations were measured only at one point in time; it is likely that change in caregiver quality of life is associated with longer duration of caregiving. More severe dementia was highly associated with greater caregiving assistance with ADLs, although we hypothesized that the associations of dementia severity would be broader, spanning more dimensions of caregiver quality of life.

Stronger endorsements of spirituality and faith and of benefits of caregiving was positively associated with being a non-white caregiver, as hypothesized, and corroborating data from our earlier focus groups of African American and of Hispanic caregivers, which guided us to include these caregiving quality-of-life dimensions in the measure. The findings also emphasize the importance of including dimensions that are relevant to a diverse spectrum of caregivers.

There are limitations of the study that are important to acknowledge. There were not enough Spanish-language surveys to assess language equivalence across English and Spanish respondents. We recruited a convenience sample of caregivers in one geographic region, and there is potential bias in our sampling frame that could affect the generalizability of results. The single item on dementia severity was based on carer self-report and while it has face validity, its reliability and validity are unknown. Only 6 of 10 test-retest reliability point estimates exceeded the cutoff typically recommended as meeting standards for group comparisons [28]. However, we note that confidence intervals around the estimates were wide, and while we attempted to identify a subset less likely to have actually had change in quality of life by setting a cap on the testretest interval and restricting to those who changed minimally on an external criterion variable, true change may have attenuated these estimates.

Because this instrument is targeted for dementia caregivers, future research should include administration of a brief generic measure of quality of life, to assess whether the generic health measure provides complementary information to this measure that broadly assesses both non-health-related and health-related aspects of quality of life of dementia carers. Future research efforts should also focus on assessing test-retest reliability in a larger sample to obtain more precise estimates, identifying a subset of items that performs as well as this 80 -item version, a more extensive analysis of construct validity, evaluation of a self-administered version, and assessment of responsiveness to change.

\section{Conclusion}

These preliminary results, while promising, should be followed by subsequent evaluation of test-retest reliability, construct validity, and responsiveness to change of this quality-of-life measure that is grounded in concerns of caregivers from diverse ethnicities. 


\section{Competing interests}

The authors declare that they have no competing interests.

\section{Authors' contributions}

BGV planned the study, supervised data analyses, and wrote the paper. $\mathrm{RDH}$ also contributed to planning of the study, supervised data analyses, and contributed to revision of the paper. MLM helped design and supervised the research protocol, and contributed to writing the paper. SDV helped design and carried out the statistical analyses, and wrote the paper. LJF and TS helped with study planning and contributed to revision of the paper. All authors read and approved the final manuscript.

\section{Additional material}

\section{Additional file 1}

CGQOL 80-item Measure. Final version of the 80-item Caregiver-Targeted Measure of Quality of Life for Dementia Caregivers (CGQOL). Click here for file

[http://www.biomedcentral.com/content/supplementary/14777525-7-56-S1.pdf]

\section{Additional file 2}

CGQOL Scoring Manual. Scoring Manual for Caregiver-Targeted Measure of Quality of Life for Dementia Caregivers (CGQOL).

Click here for file

[http://www.biomedcentral.com/content/supplementary/14777525-7-56-S2.pdf]

\section{Additional file 3}

Table S1. Associations between caregiver and patient characteristics and caregiver quality of life scores. Associations between caregiver and patient characteristics and caregiver quality of life scores.

Click here for file

[http://www.biomedcentral.com/content/supplementary/14777525-7-56-S3.pdf]

\section{Acknowledgements}

This study was funded by the State of California, Department of Public Health through the UCLA Alzheimer's Disease Research Center of California (grant \#06-553 I4). Dr. Hays was supported in part by the UCLA Resource Center for Minority Aging Research/Center for Health Improvement in Minority Elderly (RCMAR/CHIME), NIH/NIA Grant Award Number P30AG021684, and by UCLA/DREW Project EXPORT, National Institutes of Health, National Center on Minority Health \& Health Disparities, (P20MD000I 48 and P20MD000I82). The funding agencies for this study had no role in its design, collection, analysis, and interpretation of data, writing of the manuscript or the decision to submit the manuscript for publication.

We would like to extend our gratitude to the agencies serving dementia caregivers throughout Southern California who assisted us with our recruitment efforts and in particular to Michele Carter, RN, of UCLA, and Monica Moore, MSG, of the Alzheimer's Association California Southland Chapter. Other agencies that provided invaluable assistance include the Alzheimer's Association Coachella Valley Regional Office, Alzheimer's
Association San Diego/Imperial Chapter, Southern Caregiver Resource Center (San Diego), WISE Senior Center (Santa Monica), and SCAN HealthPlan (Long Beach).

\section{References}

I. Hebert LE, Scherr PA, Bienias JL, Bennett DA, Evans DA: Alzheimer disease in the US population: prevalence estimates using the 2000 census. Arch Neurol 2003, 60: I I 9-II 22.

2. National Institute on Aging: Progress Report on Alzheimer's Disease 2004-2005. (NIH Publication No. 05-5724) Washington, DC: US Government Printing Office; 2005.

3. Thomas P, Lalloue F, Preux P, Hazif-Thomas C, Pariel S, Inscale R, Belmin J, Clement J: Dementia patients caregivers quality of life: the PIXEL study. Int J Geriatr Psychiatry 2006, 21:50-56.

4. Schulz R, Martire LM: Family caregiving of persons with dementia: prevalence, health effects, and support strategies. Am J Geriatr Psychiatry. 2004, I 2(3):240-249.

5. Pinquart M, Sörensen S: Associations of stressors and uplifts of caregiving with caregiver burden and depressive mood: a meta-analysis. J Gerontol B Psychol Sci Soc Sci. 2003, 58(2):PII2-PI 28.

6. Chang $B$ : Cognitive-behavioral intervention for homebound caregivers of persons with dementia. Nurs Res 1999, 48: $173-182$.

7. Gilliard J: Ripples of stress across the generations. J Dementia Care 1996, 4:16-18.

8. Bass D, McClendon M, Deimling G, Mukherjee S: The influence of a diagnosed mental impairment on family caregiver strain. J Gerontol 1994, 49:SI 46-155.

9. Zarit SH, Todd PA, Zarit JM: Subjective burden of husbands and wives as caregivers: a longitudinal study. Gerontologist 1986, 26:260-266.

10. Zarit SH, Reever KE, Bach-Peterson J: Relatives of impaired elderly: correlates of feelings of burden. Gerontologist 1980, 20:649-655.

II. Radloff LS: The CES-D Scale: a self-report depression scale for research in the general population. Appl Psychol Meas 1977, I:385-40I.

12. Yesavage J: Geriatric Depression Scale. Psychopharmacol Bull 1988, 24:709-7|I.

13. Zung WW: A self-rating depression scale. Arch Gen Psychiatry 1965, I 2:63-70

14. Chappell NL, Reid RC: Burden and well-being among caregivers: examining the distinction. Gerontologist 2002, 42:772-780.

15. Vellone E, Piras G, Talucci C, Cohen M: Quality of life for caregivers of people with Alzheimer's disease. J Adv Nurs 2008, 61:222-231.

16. Euroqol Group: Euroqol: a new facility for the measurement of health related quality of life. Health Policy 1990, 16:199-208.

17. Torrance G, Feeny D, Furlong W, Barr R, Zhang Y, Wang Q: Multiattribute utility function for a comprehensive health status classification system. Health Utilities Index Mark 2. Med Care 1996, 34:702-722.

18. Ware J: SF-36 health survey: manual and interpretation guide The Health Institute, New England Medical Center; 1993.

19. Vickrey BG, Strickland TL, Fitten LJ, Adams GR, Ortiz F, Hays RD: Ethnic variation in dementia caregiving experiences: insights from focus groups. J Hum Behav Soc Environ 2007, I5(2/ 3):233-250.

20. Beekly DL, Ramos EM, Lee WW, Deitrich WD, Jacka ME, Wu J, Hubbard JL, Koepsell TD, Morris JC, WA K, NIA Alzheimer's Disease Centers: The National Alzheimer's Coordinating Center (NACC) database: the uniform data set. Alzheimer Dis Assoc Disord 2007, 21:249-258.

21. Stewart AL, Greenfield S, Hays RD, Wells K, Rogers WH, Berry SD, McGlynn EA, Ware JE Jr: Functional status and well-being of patients with chronic conditions. Results from the Medical Outcomes Study. JAMA 1989, 262:907-913.

22. Hui CH, Triandis HC: Measurement in cross-cultural psychology: a review and comparison of strategies. J Cross Cult Psychol 1985, 16:131-152.

23. Sudman S, Bradburn NM, Schwarz N: Thinking about Answers: The Application of Cognitive Processes to Survey Methodology San Francisco: Jossey-Bass Publishers; 1996. 
24. Stewart AL, Hays RD, Ware JE Jr: Methods of Constructing Health Measures. In Measuring Functioning and Well-Being Edited by: Stewart A, Ware JE Jr. Durham, NC: Duke University Press; 1992.

25. Hays RD, Wang E: Multitrait scaling program: MULTI. Proceedings of the Seventeenth Annual SAS Users Group International Conference. Honolulu, $\mathrm{HI} 1992$.

26. Cronbach L: Coefficient alpha and the internal structure of tests. Psychometrika 195I, 16:297-334.

27. Baumgarten M, Battista R, Infante-Rivard C, Hanley J, Becker R, Gauthier S: The psychological and physical health of family members caring for an elderly person with dementia. J Clin Epidemiol 1992, 45:61-70.

28. Hays RD, Revicki D: Reliability and validity (including responsiveness). In Assessing Quality of Life in Clinical Trials 2 nd edition. Edited by: Fayers P, Hays RD. New York: Oxford University Press; 2005.

Publish with Bio Med Central and every scientist can read your work free of charge

"BioMed Central will be the most significant development for disseminating the results of biomedical research in our lifetime. "

Sir Paul Nurse, Cancer Research UK

Your research papers will be:

- available free of charge to the entire biomedical community

- peer reviewed and published immediately upon acceptance

- cited in PubMed and archived on PubMed Central

- yours - you keep the copyright

Submit your manuscript here:

http://www.biomedcentral.com/info/publishing_adv.asp
BioMedcentral 